\title{
ANALISIS DRUG RELATED PROBLEMS (DRPS) PADA PASIEN PENYAKIT GINJAL KRONIK (PGK) RAWAT INAP DI SEBUAH RUMAH SAKIT DI BALI
}

\section{ANALYSIS OF DRUG RELATED PROBLEMS (DRPS) OF CHRONIC KIDNEY DISEASE (CKD) INPATIENTS IN A HOSPITAL IN BALI}

\author{
N.P. ARYATI SURYANINGSIH**, P. EKA ARIMBAWA*, N.P. WINTARIANI*, \\ DEWI PUSPITA APSARI* \\ *Program Studi Farmasi Klinis, Institut Ilmu Kesehatan Medika Persada Bali
}

\begin{abstract}
Abstrak: Pasien penyakit ginjal kronik (PGK) memiliki risiko mengalami masalah-masalah terkait obat atau Drug Related Problems (DRPs). Penelitian bertujuan untuk mengetahui frekuensi dan jenis terjadinya DRPs pada pasien PGK stage 3,4, dan 5 rawat inap di sebuah Rumah Sakit di Bali serta mengetahui hal-hal yang menyebabkan terjadinya DRPs. Penelitian ini dilakukan dalam dua tahapan dengan dua pendekatan yang berkesinambungan pendekatan kuantitatif dan kualitatif. Pada tahap kuantitatif dilakukan secara observasional dan tahap kualitatif melalui wawancara dengan tenaga kesehatan. Sebanyak 58 pasien yang diikuti secara prospektif, yang kemudian dikelompokkan ke dalam stage 3, 4 dan 5. DRPs tersering adalah Reaksi Obat yang Tidak Dikehendaki (ROTD) sebanyak 68,39\% dan penyebab (causes) tersering adalah terkait pemilihan dosis sebanyak 38,55\% dan terkait dengan asuransi sebesar 5,16\%. Hal-hal yang mempengaruhi terjadinya DRPs yaitu kebijakan, ketersediaan obat, komunikasi, keterbatasan sumber daya, error atau kesalahan tidak disengaja, pengetahuan dan persepsi terhadap outcome. DRPs yang paling sering terjadi adalah (ROTD) dengan penyebab yang paling sering pemilihan dosis selain itu disebabkan karena pemilihan obat, bentuk sediaan obat dan proses penggunaan obat. Perlunya adanya farmasi di ruangan yang bertugas untuk melihat terapi dan obat-obatan yang diterima pasien.
\end{abstract}

Kata kunci: Drug Related Problem, Penyakit Ginjal Kronik

\begin{abstract}
Patients with Chronic Kidney Disease (CKD) are prone to Drug Related Problems (DRPs). The study aims to determine the frequency and types of DRPs in patients with CKD stage 3,4, and 5 in a hospital in Bali as well as to investigate the factors contributing to the DRPs. The research using quantitative and qualitative approaches.The quantitative phase isobservational and descriptive. The qualitative phase used interviews with health professionals. Fifthy eight patients were followed to determine DRPs. The most common DRPs is Adverse Drug Reaction (ADR) (68.39\%) and the cause is the most common dose-related error as much as $38.55 \%$ and associated with insurance at $5.16 \%$. Factors contributing to the occurrence of DRPs are policy, drug availability, communications, resource constraints, error or unintentional error, and knowledge and perception of the outcome. The most common DRPs is ADR. The cause of the DRP is related to dose selection is most frequently in addition to that caused of a drug selection, drug forms and drug use process. It need a pharmacy in the ward to see therapies and medications for patients.
\end{abstract}

Keywords: Chronic Kidney Disease, Drug Related Problem

\section{PENDAHULUAN}

Penyakit Ginjal Kronik (PGK) merupakan masalah kesehatan masyarakat di seluruh dunia dengan peningkatan insiden dan prevalensi, outcome yang buruk serta biaya yang tinggi. Penyakit ginjal kronik ialah adanya kerusakan ginjal dan/atau penurunan fungsi ginjal yang dinyatakan dengan Laju Filtrasi Glomerolus (LFG), yang terjadi selama tiga bulan atau lebih dari tiga bulan. Kerusakan ginjal biasanya ditentukan dengan adanya proteinuria yang persisten, gangguan struktur dan kelainan radiologis Penyakit Ginjal Kronik dapat berkembang menjadi gagal ginjal dan penyakit kardiovaskular. (Levey AS et al 2003)

Bukti terbaru, berdasarkan Levey AS et al (2003) menyebutkan bahwa dampak buruk tersebut dapat dicegah atau ditunda dengan deteksi dan pengobatan dini. Berdasarkan penelitian

\footnotetext{
•email korespondensi: aquarius_bali87@yahoo.co.id
} 
Manley HJ (2010) Pengobatan yang diterima pada pasien PGK bertujuan untuk mengobati penyakitpenyakit terkait, memperlambat penyakit, dan untuk meminimalkan tingkat morbiditas serta mortalitas. Jenis obat yang diterima sangat heterogen. Berdasarkan Petter WS dan Churchwell MD Pasien PGK rata-rata menerima sepuluh sampai dua belas obat atau bahkan lebih dan mungkin perlu diminum hingga beberapa kali dalam sehari. Selain itu pasien PGK juga mengalami perubahan farmakokinetika yang meliputi perubahan Absorpsi, Distribusi, Metabolisme, dan Eleminasi (ADME). Perubahan ADME pada pasien PGK ini dapat mengakibatkan terjadinya perubahan dalam disposisi obat dan efek farmakologisnya. Jumlah obat yang digunakan merupakan faktor risiko yang secara signifikan sangat mempengaruhi munculnya masalahmasalah terkait obat atau Drug Related Problem (DRPs). (Hasaan Y, 2009)

Pharmaceutical Care Network Europe Foundation menyatakan Drug Related Problem didefinisikan sebagai suatu kejadian atau kondisi yang melibatkan terapi obat secara aktual atau potensial mengganggu hasil klinis kesehatan (health outcome) yang diinginkan. DRPs dapat meningkatkan frekuensi masuk rumah sakit, morbiditas, dan mortalitas. Penelitian yang dilakukan Blix HS dan Garbe DW menyatakan Optimalisasi terapi obat, dengan mencegah DRPs dapat meminimalkan biaya kesehatan, yang mana secara potensial akan menyelamatkan hidup dan meningkatkan kualitas hidup pasien. Menurut Cipolle RJ 1998, dengan mengatasi DRPs pada individu pasien, masalah sosial akibat morbiditas dan mortalitas terkait obat juga dapat ditekan. Layanan farmasi klinis dapat mengatasi masalah ini. Beberapa penelitian menunjukkan bahwa kontribusi farmasi klinis secara signifikan dapat mengurangi DRPs. Penelitian Blix HS, 2004 menyatakan dengan adanya intervensi dari farmasi klinis dalam mengidentifikasi DRPs dan memberikan saran terkait DRPs yang ditemukan, frekuensi DRPs akan berkurang, sehingga dapat memberikan efek farmakoterapi yang lebih baik bagi pasien. Menurut Kaboli PJ 2006, kehadiran farmasi klinis di rumah sakit juga dapat meningkatkan pengetahuan dan ketepatan penggunaan obat sehingga meningkatkan outcome pasien. Empat belas penelitian menunjukkan bahwa intervensi dari farmasi klinis dapat mengurangi kejadian DRPs, di mana diskusi antara farmasi klinis dengan dokter dalam peresepan dapat mengurangi kejadian Reaksi Obat yang Tidak Dikehendaki (ROTD). Cipolle RJ dan Blix HS menyatakan ROTD merupakan salah satu kategori utama dari masalah DRPs. Ada empat hal filosofi pelayanan farmasi klinis menurut Nicholas Barber yaitu, memenuhi memaksimalkan efek terapi, meminimalkan risiko pengobatan, meminimumkan biaya pengobatan, dan menghormati pilihan pasien. Tan CK (2003)

Pasien PGK sangat berisiko mengalami DRPs. Penelitian Blix et al tahun 2004, menunjukkan sebanyak $81 \%$ pasien PGK mengalami DRPs di mana DRPs yang paling sering terjadi dilaporkan berhubungan dengan dosis sebanyak $35.1 \%$, obat tidak optimal $21.4 \%$, memerlukan obat tambahan sebanyak $19.7 \%$, dan obat tidak diperlukan sebanyak 16,7\%. Tahun 2006 penelitian Blix et al juga menunjukkan ada $62 \%$ pasien PGK stage 3,4, dan 5 yang mengalami DRPs yang berkaitan dengan penggunaan obatobat yang berisiko terhadap ginjal dan DRPs yang paling sering terjadi adalah berhubungan dengan penggunaan obat yang harus dihindari sebanyak 27 $\%$ serta diperlukannya adjusment dosis sebanyak 19\%. Penelitian Silvy Irawati pada PGK stage 3,4, dan 5 tahun 2008 menemukan 452 DRP dari 84 pasien. Kategori DRPs tersering adalah masalah pemilihan obat sebanyak $54,2 \%$, dengan jenis DRPs tidak adanya indikasi yang jelas obat yang diresepkan, memberikan kontribusi terbesar yaitu $26,1 \%$. Selain itu ditemukan juga bahwa ada hubungan positif signifikan lemah antara faktor risiko (polifarmasi, penggunaan obat dengan indeks terapi sempit, dan penggunaan nasogastric tube) dengan jumlah DRP. Penelitian Manley et al tahun 2005 pada pasien hemodialisis menunjukkan masalah terkait obat yang umum terjadi adalah kesalahan terkait dosis sebanyak 20,4\% (subterapetik dosis 11,2\% dan overdosis 9,2\%).

Prevalensi PGK di daerah ini sebanyak 56\% pada tahun 2007 yang dilihat dari berbagai letak geografis daerah, menurut Widiana IGR (2007). Menurut para klinisi di rumah Rumah Sakit ini, lebih dari $50 \%$ di bangsal penyakit dalam diisi oleh pasien PGK, namun belum pernah dilakukan penelitian mengenai DRPs pada pasien PGK. DRPs saat ini menjadi permasalahan yang dibahas di bidang kesehatan, karena diketahui dapat mengurangi kualitas hidup pasien, dan meningkatkan kejadian morbiditas serta mortalitas. Untuk itu perlu diidentifikasi frekuensi dan jenis DRPs yang sering terjadi, outcome klinis dari DRPs. Selain itu perlu dilakukan kajian lebih lanjut untuk mengetahui hal-hal apa saja yang menyebabkan terjadinya DRPs, karena dari beberapa penelitian terkait DRPs yang ada hanya melihat angka kejadian DRPs dan hubungan faktor risiko dengan kejadian DRPs. Pasien yang diikutkan dalam penelitian ini adalah PGK stage 
lanjut yaitu stage 3,4 , dan 5 (laju filtrasi glomerolusnya kurang dari $59 \mathrm{ml} /$ menit), karena kelompok pasien tersebut yang menjalani rawat inap dan memiliki faktor risiko klinis/farmakologis yang lebih banyak dibandingkan stage 1 dan 2. Blix HS (2004)

\section{METODE PENELITIAN}

Penelitian ini untuk melihat seberapa besar frekuensi terjadinya DRPs pada pasien PGK stage 3,4 , dan 5 rawat inap di sebuah Rumah Sakit di Denpasar, Apa saja jenis DRP yang sering dialami pada pasien PGK stage 3,4, dan 5 rawat inap di sebuah Rumah Sakit di Denpasar, dan hal - hal apa saja yang menyebabkan terjadinya DRPs. Penelitian dilakukan dalam dua tahapan dengan dua pendekatan yang berkesinambungan pendekatan kuantitatif dan kualitatif. Tahapan kuantitatif dilakukan secara observasionaldeskriptif dan bertujuan untuk mengetahui jenis dan frekuensi terjadinya DRPs pada pasien PGK stage 3,4, dan 5 yang sedang menjalani rawat inap di sebuah Rumah Sakit di Bali. Tahapan kualitatif dilakukan untuk menggali informasi yang tidak diperoleh pada saat observasi, melakukan konfirmasi temuan DRP dengan tenaga kesehatan untuk mengetahui penyebab DRP. Pendekatan kualitatif dilakukan melalui wawancara informal dengan tenaga kesehatan.

Teknik pengambilan sampel yang digunakan adalah total sampling, yaitu mengambil keseluruhan pasien yang ada di bangsal interna di sebuah Rumah Sakit di Bali yang sesuai dengan kriteria penelitian. Teknik pengumpulan data yang digunakan dalam penelitian ini adalah observasi, kajian terhadap rekam medis pasien rawat inap di sebuah Rumah Sakit di Bali dan wawancara informal kepada tenaga kesehatan, termasuk diskusi dengan dokter.

Data kuantitatif yang diperoleh melalui observasi akan dianalisis dengan menggunakan PCNE V 6.2 untuk mengkategorikan DRPs. Kemudian dianalisis Analisis jenis dan frekuensi DRPs dilakukan dengan statisik deskriptif menggunakan program SPSS versi 17, Statistik deskriptif digambarkan dalam proporsi, frekuensi, rata-rata (mean), dan deviasi standar (standart deviation). Data kualitatif yang diperoleh dari wawancara didokumentasikan dalam bentuk catatan lapangan (field note). Setelah itu peneliti mengidentifikasi tema atau kategori dari catatan lapangan tersebut dengan cara membaca data tersebut berulang-ulang, memberikan kode, dan mengidentifikasi tema-tema untuk menjawab rumusan masalah, yaitu untuk mengetahui penyebab-penyebab DRPs. Analisis kualitatif dilakukan oleh dua orang secara terpisah, kemudian hasil analisis didiskusikan sampai tercapai konsensus.

\section{HASIL DAN PEMBAHASAN}

1. Karakteristik responden

Tabel 1. Jenis Kelamin Responden

\begin{tabular}{cccc}
\hline Pasien & L & P & $\sum$ \\
\hline Total & 34 & 24 & 58 \\
\hline$\%$ & 58,62 & 41,38 & 100 \\
\hline
\end{tabular}

Tabel 2. Usia Responden

\begin{tabular}{ccccccc}
\hline Usia & $\mathbf{1 5 - 3 0}$ & $\mathbf{3 1 - 4 5}$ & $\mathbf{4 6 - 6 0}$ & $\mathbf{6 1 - 7 5}$ & $\mathbf{7 6 - 9 0}$ & $\Sigma$ \\
\hline Total & 3 & 14 & 24 & 15 & 2 & 58 \\
\hline $\boldsymbol{\%}$ & 5,17 & 24,14 & 41,38 & 25,86 & 3,45 & 100 \\
\hline
\end{tabular}

Berdasarkan tabel 1 dapat diketahui bahwa sebagian besar responden berjenis kelamin lakilaki 34 orang $(58,62 \%)$. Dilihat dari karakteristik umur sebagian besar responden berada dalam rentang 46-60 tahun 24 orang $(41,38 \%)$.

2. Frekuensi DRPs pada pasien PGK stage 3,4 dan 5 Rawat Inap di Sebuah Rumah Sakit di Bali.

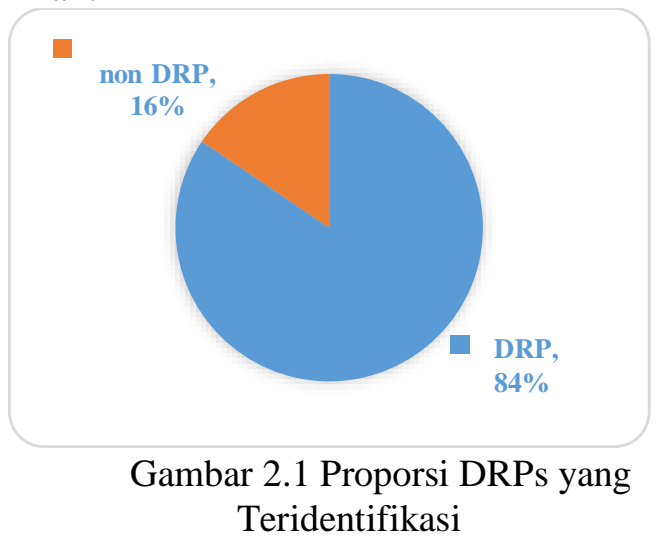

Dari gambar 1 dapat dilihat dari hasil observasi dan wawancara diperoleh 58 pasien berdasarkan analisis DRPs ada 9 pasien yang tidak mengalami DRPs, dan 49 pasien mengalami DRPs.

3. Frekuensi DRPs pada pasien PGK stage 3,4 dan 5 Rawat Inap di Sebuah Rumah Sakit di Bali. 
Tabel 3. Frekuensi DRPs pasien PGK

\begin{tabular}{ccc}
\hline Jumlah DRPs & Jumlah Pasien & $\mathbf{\%}$ \\
\hline $\mathbf{1}$ & 13 & 26,50 \\
$\mathbf{2}$ & 10 & 20,40 \\
\hline $\mathbf{3}$ & 5 & 10,20 \\
\hline $\mathbf{4}$ & 7 & 14,28 \\
\hline $\mathbf{5}$ & 8 & 16,32 \\
\hline $\mathbf{6}$ & 4 & 8,16 \\
\hline $\mathbf{7}$ & 1 & 2,04 \\
\hline $\mathbf{8}$ & 1 & \\
\hline Mean & & 3,16 \\
\hline SD & & 1,92 \\
\hline
\end{tabular}

Dari 49 pasien yang mengalamai DRPs, rata-rata DRPs yang teridentifikasi sebanyak 2,67 dengan rentang 1 sampai dengan 8 DRPs seperti yang digambarkan pada tabel 4.3.

DRPs (problem) tersering adalah Reaksi Obat yang Tidak Dikehendaki (ROTD) sebanyak 68,39\%. ROTD yang ditemukan pada penelitian ini terkait ROTD berupa reaksi non alergi sebanyak 61,29\% dan ROTD berupa reaksi toksik 7,10\%. Pada penelitian ini total DRP yang teridentifikasi 155 DRPs namun tidak semua DRPs yang terjadi ini memberikan pengaruh ke kondisi klinis pasien, ada DRPs yang aktual terjadi dan potensial. DRPs yang potensial terjadi yang mana pada saat DRPs itu muncul, saat itu juga dapat dilihat outcome secara klinisnya pada pasien.

Hasil analisis DRPs pada penelitian ini berbeda dengan beberapa penelitian sebelumnya. Pada penelitian ini DRPs yang teridentifikasi sebanyak 155 problem dengan 179 causes. Hal ini disebabkan karena satu problem DRPs boleh memiliki lebih dari satu causa sehingga causes yang teridentifikasi lebih banyak. Rumah sakit ini merupakan rumah sakit rujukan tahap II, sehingga seringkali pasien yang ditemui pasein PGK dengan komplikasi. Penelitian Hasan Y pada tahun 2009 menyatakan terapi yang diterima pada pasien ini, sangatlah kompleks, dan jumlah obat yang banyak diketahui sangat mempengaruhi terjadinya DRPs. DRPs yang ditemukan tidak semua nya merupakan DRPs yang aktual terjadi pada pasien, dimana dari 155 problem DRPs yang ditemukan 26 (16,77\%) merupakan DRPs aktual dan 129
$(83,23 \%)$ merupakan DRPs yang potensial terjadi pada pasien. Obat yang terlibat dalam DRPs aktual ialah penggunaan kaptopril, kombinasi kaptopril dengan antasida, insulin, kombinasi kaptopril dengan nifedipin, kolkisin dan penggunaan antibiotika ciprofloksasin, seftasidim, meropenem, levofloksasin, dan eritromisin.

DRPs yang paling sering terjadi, baik yang aktual maupun potensial terjadi terkait dengan reaksi obat yang tidak dikehendaki (ROTD) sebanyak 68,39 \% yaitu ROTD berupa reaksi non alergi 61,29\% dan ROTD berupa reaksi toksik 7,10\%. Problem yang masuk dalam ROTD non-alergi seperti timbulnya efek samping diare karena penggunaan kolkisin. Problem lain yang ditemukan terkait dengan efektifitas terapi seperti efek obat tidak optimal dan adanya indikasi tidak dirawat juga ditemukan pada penelitian ini. Problem yang masuk dalam efek terapi tidak optimal adalah pada pasien yang telah menerima terapi, namun efek belum optimal tercapai. DRPs Indikasi yang tidak dirawat pada penelitian ini ialah tidak diberikannya terapi preventif aspirin (antiplatelet) pada pasien penyakit ginjal kronik dengan kondisi penyakit penyerta diabetes. Problem DRPs lain yang ditemukan yaitu terkait biaya terapi sebanyak $3,87 \%$ dan masalah lain-lain 1,29\%.

Penelitian sebelumnya tentang DRPs di rumah sakit di Surabaya oleh Irawati S, 2008 menemukan enam problem DRPs yang secara berturut-turut adalah masalah pemilihan obat, pemberian dosis, masalah ROTD, lainnya, penggunaan obat dan interaksi obat. Masalah pemilihan obat adalah masalah yang paling sering ditemukan sebesar $54,2 \%$ yaitu dengan kategori tidak adanya obat yang diresepkan untuk indikasi yang jelas 26,3\% dan outcome klinis dari DRPs sebagian besar tidak terjadi apa-apa 63,1\%.

Berdasarkan hasil wawancara yang dilakukan ditemukan beberapa faktor yang menyebabkan terjadinya DRPs, yaitu kebijakan, komunikasi, ketersediaan obat, keterbatasan sumber daya dalam memberikan, error/kesalahan tidak disengaja, pengetahuan dan persepsi terhadap outcome klinis pasien. 
Penelitian sebelumnya menyebutkan bahwa masalah perlengkapan, komunikasi, kurangnya pelatihan, pengalaman, pengetahuan, masalah individu serta masalah budaya merupakan faktor penyebab kesalahan pengobatan intavena dan penyebab kesalahan pengobatan secara umum (Taxis K, 2003).

Selain penelitian ini, belum ada penelitian khusus untuk mencari faktor-faktor yang menyebabkan terjadinya DRPs. Penelitian sebelumnya yang dilakukan di Surabaya mengkaitkan terjadinya DRPs karena ketersediaan obat yang terbatas dari asuransi kesehatan serta adanya syarat pemeriksaan laboratorium terlebih dahulu sebelum meresepkan obat-obat tertentu (Irawati S, 2008).

Dua hal tersebut pada penelitian ini sama dengan faktor ketersediaan dan faktor kebijakan terapi, namun lima faktor lain yang tidak dilaporkan dalam penelitian lain yaitu komunikasi antara tenaga kesehatan; ketersediaan sumber daya dan kesalahan yang terjadi secara tidak sengaja, pengetahuan dan persepsi terhadap outcome klinis pasien.

Pengetahuan menjadi faktor yang mempengaruhi terjadinya DRPs yang paling sering yaitu Reaksi Obat Yang Tidak Dikehendaki dengan causes pemilihan dosis $(38,55 \%)$. Pengetahuan sangat mempengaruhi klinisi dalam memberikan terapi terkait pilihan, dosis serta pemilihan bentuk sediaan bagi pasien. Suatu penelitian yang dilakukan Dean B, 2002 menyebutkan bahwa tidak adanya pengetahuan, terutama tetang dosis dapat mempengaruhi kesalahan dalam peresepan. Menurut Churchwell MD dan Blix HS pada pasien penyakit ginjal kronik penyesuaian sangat diperlukan, namun hal ini sering diabaikan oleh klinisi. Berdasarkan penelitian di rumah sakit Penang, pemilihan dosis yang tidak sesuai menjadi masalah yang paling penting pada pasien dengan gangguan ginjal (Mahmoud MA, 2010).

\section{SIMPULAN}

Hasil kuantitatif analisis DRPs pada penelitian ini memberikan hasil mengenai DRPs yang terjadi pada pasien PGK, frekuensi terjadinya
DRPs. DRPs tersering yang terjadi pada pasien di rumah sakit di Bali adalah P 2 terkait dengan Reaksi Obat yang tidak dikehendaki 68,39\% dan $1,29 \%$ penyebab DRPs tersering karena C3 pemilihan dosis $38,55 \%$ dan $\mathrm{C} 1$ pemilihan obat $18,99 \%$, dengan outcome klinisi hasil pemantauan DRPs pada pasien sebagian besar tidak terjadi apaapa. Frekuensi terjadinya DRPs sebesar $84 \%$ dari 58 pasien.

\section{DAFTAR PUSTAKA}

1. Levey AS, Coresh J, Balk E, Kausz AT, Levin A, Steffes MW,et al. National kidney foundation practice guidelines for chronic kidney disease: evaluation, classification and stratification.Ann Intern Med. 2003;139:137147

2. Manley HJ, Pai AB, Assimon MM, Baccchus $\mathrm{S}$, Cardone KE. Medical-related problems in CKD [Internet]. ScienceDirect;2010 [cited 201114 april 2011] Available from:

http://www.sciencedirect.com/science/article/ pii/S1548559510001151

3. Petter WS. Improving medication safety in chronic kidney disease patients on dialysis through medication reconciliation. Adv in Chronic Kidney Dis. 2010; 17(5):413-419.

4. Churchwell MD, Mueller BA. Selected pharmacokinetic issues in-patient with chronic kidney disease. Blood Purif 2007; 25 : 133-138.

5. Hasaan Y, Al-Ramahi RJ, Abd Aziz N, Ghazali R. Drug use and dosing in chronic kidney disease. Ann Acad Med Singapore 2009; 38: 1095-103.

6. Pharmaceutical Care Network Europe Foundation. 2003-2010. 2010; 14: 1-4

7. Blix HS, Viktil KK, Moger TA, Reikvam A. Use of renal risk drugs in hospitalised patients with impaired renal function - an underestimated problem. Nephrol Dial Transplant (2006) 21:3164-3171.

8. Grabe DW. Drug related problem in the endstage renal disease population. Medscape Pharmacist. 2000;1(2)

9. Cipolle RJ, Strand LM, Moley PC. Identifying, resolving and preventing drug therapy problems: the pharmacist's responsibility. in : pharmaceutical care practice. New York: McGraw-Hill;1998.p7379

10. Blix HS, Viktil KK, Reikvam A, Moger TA, Hjemaas BJ, Pretsch P, et al. The majority of 
hospitalised patients have drug-related problems: results from a prospective study in general hospitals. Eur J Clin Pharmacol 2004 60: 651-658.

11. Kaboli PJ, Hoth AB, McClimon BJ, Schnipper JL. Clinical pharmacist and inpatient medical care a systematic review.Arch Intern Med. 2006;166:955-964

12. Tan CK, Ahaditomo, Prayitno A. Pelaksanaan pelayanan farmasi klinis. Dalam: Aslam M, Tan CK, Prayitno A, editors. Farmasi Klinis. Jakarta: PT Elex Media Komputindo;2003. p.17-19

13. Blix HS, Viktil KK, Reikvam A, Morger TA, Hjemaas BJ, Pretsch P, et al. The majority of hospitalized patients with have drug-related problem: results from a prospective study in general hospitals.Eur J Clin Pharmacol 2004 Okt 2; 60: 651-658.

14. Irawati $\mathrm{S}$. Analisis masalah-masalah terkait obat (Drug Related Problem/DRPs) Pada pasien Penyakit Ginjal Kronik yang mengalami rawat Inap di Rumah Sakit Angkatan Laut DR Ramelan Surabaya
[Tesis]. Indonesia. Universitas Surabaya; 2008.

15. Manley HJ, Cannella CA, Bailie GR. Medication related problems in ambulatory hemodialysis patients: a pooled analysis [abstract]. Am J Kidney Dis. 2005 Oktober; 46(4): 669-80.

16. Widiana IGR. Distribusi geografis penyakit ginjal kronik di bali: komparasi formula cockroft-gault dan formula modification of diet in renal disease. J Peny Dalam 2007 September ; 8(3):198-204

17. Taxis K, Barber N. Causes of intravenous medication errors: an ethnographic study. Qual Saf Health Care. 2003 Oktober ;12(5): 343-347.

18. Dean B, Schachter M, Vincent C, Barber N. Causes of prescribing errors in hospital inpatients: a prospective study. Lancet. 2002 April 20; 359 : 1373-78

19. Mahmoud MA. Drug Therapy Problems And Quality Of Life In Patients With Chronic Kidney Disease. [Tesis]. Malaysia. Universiti Sains Malaysia; 2010 